\section{Nubian ibex}

I would like to add to the information given in the article 'Nubian ibex in the Eastern Desert, Egypt' (Oryx, 20, 176-177). Israeli soldiers who were stationed at Jebel Ataqa (29 55'N $\left.3220^{\prime} \mathrm{E}\right)$ reported that during November 1973 they observed a group of Nubian ibexes on that mountain. The last report of ibexes from this area dates back to 1866 (Osborn and Helmy, 1980).

\section{Reference}

Osborn, D.J. and Helmy, I. 1980. The contemporary land mammals of Egypt (including Sinai), Fieldiana, 5, 519.

Dr Y. Yom-Tou, George S. Wise, Faculty of Life Sciences, Department of Zoology, Tel Aviv University, Israeli.

\section{Editor's note}

Dr Yom-Tov was amongst many who wrote to correct the error in using a picture of a markhor instead of a Nubian ibex to illustrate the article in the July issue of Oryx. A correction was published in the October 1986 issue. Among the people who wrote was Dr Al-Khalili of the Arabian Gulf University who also sent a photograph taken by Dr Mustafa A. Saleh, of Bahrain University. Dr Saleh accompanied the two authors of the article on the field trip that resulted in the sighting of the Nubian ibex at Wadi el Assiut.

\section{Skins for money}

The photograph of leopard skins on sale in Lhasa (Oryx, October 1986) did not bring joy to the heart, but I can answer the question posed by the heading 'Skins for tourists?'. It is not tourists who buy these skins but the Tibetan tribesmen. They treasure the brightly coloured furs, apparently using them mainly for trimming their clothes. The skins are mainly smuggled in from Nepal and/or India and fetch a high price-from memory, about $£ 1000$ for a good one. Besides Lhasa I have also seen them on sale at the Ta'er (Kumbum) Monastery near Xining in China's Qinghai Province, and near Labrang Monastery in Gansu Province. One snow leopard skin that I saw was offered for quite a lot less than the more garish 'spotted' leopard skins. Other fur skins were also on sale at some of these places.

Nigel Sitwell, 243 King's Road, London SW3 5EL, UK. Letters

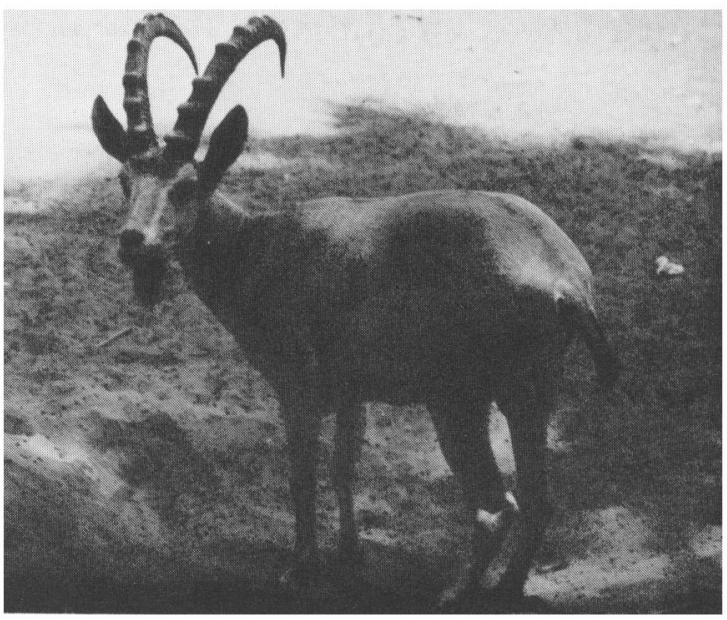

An adult male Nubian ibex Capra ibex nubiana at Al-Giza Zoo in Cairo, Egypt (Mustafa A. Saleh).

\section{Tributyltin-new legislation}

As a follow-up to my article 'The case against tributyltin' in the October 1986 issue of Oryx, some recent news may be of interest. It was announced by the Department of the Environment that from January 1987 new legislation will come into force that will reduce the amount of tributyltin allowed in co-polymer (self-polishing) paints from 7.5 per cent to 5.5 per cent. This is certainly good news, particularly as the evidence continues to accrue concerning undesirable environmental effects. In particular, Gibbs and Bryan (1986) at the Marine Biological Association, Plymouth, have now shown categorically that imposex in female dog whelks blocks, or partially blocks, the female opening and can, therefore, prevent the release of eggs. Furthermore, not only can the females not release the eggs, but the 'aborted capsules' accumulate inside the body and would appear to eventually cause premature death. Tributyltin has been shown to induce imposex, and thus the reported loss of populations of dog whelks is linked with the pollutant.

\section{Reference}

Gibbs, P.E. and Bryan, G.W. 1986. J. Mar. Biol. Ass. UK, 66, $767-777$.

Mark Simmonds, School of Biological Sciences, Queen Mary College, University of London, Mile End Road, London E1 4NS, UK. 